\title{
Antioxidant activities of aqueous extracts from 12 Chinese edible flowers in vitro and in vivo
}

\author{
Feng Wang ${ }^{a *}$, Miao Miao ${ }^{\mathrm{a}, \mathrm{b} *}$, Hui Xia ${ }^{\mathrm{a}}$, Li-Gang Yang ${ }^{\mathrm{a}}$, Shao-Kang Wang ${ }^{\mathrm{a}}$ and Gui-Ju Sun ${ }^{\mathrm{a}}$ \\ ${ }^{a}$ Key Laboratory of Environmental Medicine and Engineering of Ministry of Education, Department of Nutrition and Food Hygiene, School of \\ Public Health, Southeast University, Nanjing, China; 'b State Key Laboratory of Reproductive Medicine, Department of Nutrition, Nanjing \\ Maternity and Child Health Care Hospital Affiliated to Nanjing Medical University, Nanjing, China
}

\begin{abstract}
The antioxidant function of edible flowers have attracted increasing interest. However, information is lacking on the impact of edible flowers on oxidative injury including hypoxia-reoxygenation and hyperlipidemia. The antioxidant activities of aqueous extracts from 12 Chinese edible flowers were assessed in four different antioxidant models, including total antioxidant capacity (TAC), oxygen radical absorbance capacity (ORAC), scavenging hydroxyl radical capacity (SHRC) and scavenging superoxide anion radical capacity (SSARC). Subsequently, the potential antioxidant effects on rat cardiac microvascular endothelial cells (rCMEC) treated with hypoxia-reoxygenation and hyperlipidemia rats induced by high-fat diet were also evaluated. The highest TAC, ORAC, SHRC and SSARC were Lonicera japonica Thunb., Rosa rugosa Thunb., Chrysanthemum indicum L. and Rosa rugosa Thunb., respectively. Most aqueous extracts of edible flowers exhibited good antioxidant effects on injury of rCMEC induced by hypoxia-re-oxygenation. In addition, the aqueous extracts of Lonicera japonica Thunb., Carthamus tinctorius L., Magnolia officinalis Rehd. et Wils., Rosmarinus officinalis L. and Chrysanthemum morifolium Ramat. could suppress the build-up of oxidative stress by increasing serum superoxide dismutase, glutathion peroxidase, and reducing malonaldehyde concentration in hyperlipidemia rats. These findings provided scientific support for screening edible flowers as natural antioxidants and preventative treatments for oxidative stress-related diseases.
\end{abstract}

\section{ARTICLE HISTORY}

Received 1 September 2016 Revised 10 November 2016

Accepted 23 November 2016

\section{KEYWORDS}

Edible flowers; antioxidant activity; hypoxia-reoxygenation; hyperlipidemia

\section{Abbreviations}

GSH-Px: glutathion peroxidase; HDL-C: high density lipoprotein cholesterol; I/R: ischaemia/reperfusion; LDH: lactate dehydrogenase; LDL-C: low density lipoprotein cholesterol; MDA: malonaldehyde; ORAC: oxygen radical absorbance capacity; rCMEC: rat cardiac microvascular endothelial cells; SHRC: scavenging hydroxyl radical capacity; SOD: superoxide dismutase; SSARC: scavenging superoxide anion radical capacity; TAC: total antioxidant capacity; TC: total cholesterol; TG triacylglycerol

\section{Introduction}

There is ample evidence that free radicals, especially reactive oxygen species (ROS), play an essential role in various aspects of physiological and biochemical processes, such as cellular signal transduction, cell proliferation, differentiation and apoptosis [1,2]. However, excessive amount of ROS can produce a myriad of oxidative damages to biomolecules (e.g. lipids, proteins, DNA), which lead to many chronic diseases, including hyperlipidemia, diabetes mellitus, hypertension, ageing and cancer [3-5]. In view of the potential health risks and toxicity of synthetic antioxidants [6,7], naturally effective antioxidants have been widely concerned as preventive and treatment agents.

Many places, such as medieval France and ancient China, have the traditional habit of eating flowers to improve appearance and nutritive value of meals $[8,9]$. Most edible flowers contain flavonoids, anthocyanins, carotenoids, alkaloids, and many other phenolic compounds, which are rich in antioxidant activity [10-12]. By 2002, about 10 types of Chinese edible flowers have been allowed to be used as either health-care food or medicine by the Ministry of Health of the People's Republic of China. Recently, scented tea is becoming enormously popular in modern food regimen. Indeed, drinking scented tea has become an indispensable part

CONTACT Gui-Ju Sun gjsun@seu.edu.cn $\Theta$ Key Laboratory of Environmental Medicine and Engineering of Ministry of Education, Department of Nutrition and Food Hygiene, School of Public Health, Southeast University, Nanjing, China

*These authors contributed equally to this work.

(c) 2016 The Author(s). Published by Informa UK Limited, trading as Taylor \& Francis Group.

This is an Open Access article distributed under the terms of the Creative Commons Attribution License (http://creativecommons.org/licenses/by/4.0/), which permits unrestricted use, distribution, and reproduction in any medium, provided the original work is properly cited. 
of Chinese people's life. Nevertheless, the health effects of edible flowers remain poorly characterized. There is a paucity of information on the impact of edible flowers on oxidative injury including ischaemia/reperfusion (I/R) and hyperlipidemia.

Therefore, the purpose of the present study is to assess antioxidant activities of aqueous extract from 12 Chinese edible flowers, by measuring total antioxidant capacity (TAC), oxygen radical absorbance capacity (ORAC), scavenging hydroxyl radical capacity (SHRC) and scavenging superoxide anion radical capacity (SSARC). In addition, the potential antioxidant effects on rat cardiac microvascular endothelial cells (rCMEC) treated with hypoxia-re-oxygenation and hyperlipidemia rats induced by high-fat diet were also evaluated.

\section{Materials and methods}

\section{Antioxidant activities assay of edible flowers extracts}

A total of 12 dried edible flowers were obtained from Nanjing City in Jiangsu Province, China. Their colour, edible use and traditional medicinal use are presented in Table 1. According to the Pharmacopoeia of the People's Republic of China [13] and the Flora of China [14], the source of edible flowers was proved by the College of Food Science and Technology, Nanjing Agricultural University, China. The dried flowers were ground into fine particles with a special grinder for food processing. Each sample $(2 \mathrm{~g})$ was weighed and mixed with $10 \mathrm{ml}$ double distilled water, then ultrasonic treatment for $30 \mathrm{~min}$. The liquid supernatant were separated through centrifuging at $5000 \mathrm{rpm}$ for $30 \mathrm{~min}$ and adjusted to the final volume of $25 \mathrm{ml}$ with double distilled water for antioxidant activities analysis. The TAC, SHRC and SSARC of edible flowers extracts were assayed using commercial kits (Institute of Biological Engineering of Nanjing Jianchen, Nanjing, China) according to the manufacturer's protocol. The ORAC was determined according to the method of previous assays [15].

\section{Edible flowers extract preparation for cell and animal assay}

Each sample (300 g) was weighed and extracted with $2000 \mathrm{ml}$ boiling distilled water for 1 hour. After cooling the extracts were filtered using a filter paper, and then the filtrates were diluted to a solution of $0.3 \mathrm{~g} / \mathrm{ml}$ and stored at $4^{\circ} \mathrm{C}$ for further analysis in vitro and in vivo.

\section{Isolation of primary rCMEC}

The rCMEC were isolated as described in previous report [16]. Briefly, the Wistar rats (7-10 days) hearts were rapidly removed, rinsed, and bathed with $75 \%$ alcohol in order to inactivate endothelial cells in epicardium and endocardium. Hearts were minced and re-suspended with $2 \mathrm{ml} 0.2 \%$ type II collagenase, then incubated for $30 \mathrm{~min}$ with $37^{\circ} \mathrm{C}$. They were digested for $10 \mathrm{~min}$ with $0.02 \%$ pancreatic enzyme solution. After digestion, the cells were filtered through sterile nylon mesh, and centrifuged at $1000 \mathrm{rpm}$ for $5 \mathrm{~min}$. The cell pellet was re-suspended in $8 \mathrm{ml}$ Dulbecco's modified Eagle's medium (DMEM, Life Technologies/Gibco, Grand Island, NY) containing $10 \%$ foetal calf serum (FCS, Life Technologies/Gibco, Grand Island, NY), $100 \mathrm{U} / \mathrm{ml}$ penicillin and $100 \mu \mathrm{g} / \mathrm{ml}$ streptomycin (Life Technologies/Gibco, Gaithersburg, MD) and plated into culture flasks treated with $1 \%$ gelatin. Nonadherent cells were removed after $37^{\circ} \mathrm{C}$ for $4 \mathrm{~h}$ and discarded. The adherent cells were rCMEC. These protocols were approved by the Institutional Animal Care and Use Committee of Southeast University.

Table 1. The colour, edible use and traditional medicinal use of edible flowers.

\begin{tabular}{|c|c|c|c|}
\hline Edible flowers & Colour & Edible use & Traditional medicinal use \\
\hline Lonicera japonica Thunb. & Yellow-green & Tea, soup & Heat-clearing and detoxifying \\
\hline Jasminum sambac (L.) Aiton & White & Tea, porridge & Relieving cough and reducing sputum \\
\hline Carthamus tinctorius L. & Red & Tea, cake & Promoting blood circulation, restoring menstrual flow \\
\hline Gardenia jasminoides Ellis & Reddish brown & Tea, soup & Clearing heat and promoting diuresis \\
\hline Magnolia officinalis Rehd. et Wils. & Reddish brown & Tea & Resolving dampness with aromatics \\
\hline Rosa rugosa Thunb. & Prunosus & Tea, soup & Promoting qi circulation and relieving depression \\
\hline Rosmarinus officinalis L. & Yellow-green & Tea, natural perfume & Tranquilizing and allaying excitement \\
\hline Chrysanthemum indicum L. & Brown-yellow & Tea, cake & Heat-clearing and detoxifying \\
\hline Chrysanthemum morifolium Ramat. & Yellow-white & Tea, cake & Heat-clearing and detoxifying \\
\hline Eugenia caryophyllata Thunb. & Dark brown & Tea & Warming middle energizer descend adverse-rising \\
\hline Sophora japonica L. & Yellow & Tea, cake & Cooling blood and haemostasis \\
\hline Myosotis silvatica Ehrh. ex Hoffm. & Blue & Tea & Heat-clearing and detoxifying \\
\hline
\end{tabular}




\section{Hypoxia and re-oxygenation of primary rCMEC}

For hypoxia and re-oxygenation treatment, rCMEC were cultured in serum-free DMEM medium supplemented with $0.5 \mathrm{~mol} / \mathrm{L}$ de-oxidant sodium dithionite in $37^{\circ} \mathrm{C}$ with $5 \% \mathrm{v} / \mathrm{v} \mathrm{CO}$ incubator for $1 \mathrm{~h}$. Then, the cells were maintained in DMEM medium supplemented with $10 \%$ foetal calf serum in $37^{\circ} \mathrm{C}$ with $5 \% \mathrm{v} / \mathrm{v} \mathrm{CO}_{2}$ incubator for another $1 \mathrm{~h}$.

\section{Cell proliferation and apoptosis assay}

The rCMEC $\left(2.5 \times 10^{3} /\right.$ well $)$ were seeded in 96-well plates and divided into 14 groups, including control group (normal cells), model group (hypoxia $1 \mathrm{~h}$ then re-oxygenation $1 \mathrm{~h}$ ) and model group plus 12 edible flowers extracts (12 groups, respectively). The cells were treated with $750 \mu \mathrm{g} / \mathrm{L}$ edible flowers extracts in DMEM for $24 \mathrm{~h}$ then treated with hypoxia for $1 \mathrm{~h}$ then re-oxygenation for $1 \mathrm{~h}$. Cell proliferation was measured using MTT method.

The rCMEC $\left(2 \times 10^{5} /\right.$ well $)$ were seeded in 24 -well plates and treated in accordance with methods described above. The cell apoptosis was assessed by a flow cytometric analysis using propidium iodide (PI) (Sigma, USA) staining according to the manufacturer's protocol. Briefly, the cells were collected via trypsinization and washed with phosphate-buffered saline (PBS). The cells were fixed with $95 \%$ acetic acid and stored at $4^{\circ} \mathrm{C}$ overnight. The following day, the cells were washed with PBS, treated with RNase A $(50 \mu \mathrm{g} / \mathrm{ml})$, and stained with propidium iodide (PI) $(50 \mu \mathrm{g} / \mathrm{ml})$ for $30 \mathrm{~min}$ in the dark. The cells were subsequently analyzed via flow cytometry (CoulterEPICS-XL System II).

\section{Cell antioxidant activities assay}

The rCMEC were divided into 14 groups, including control group (normal cells), model group (hypoxia $1 \mathrm{~h}$ then re-oxygenation $1 \mathrm{~h}$ ) and model group plus 12 edible flowers extracts ( 12 groups, respectively). The cell culture supernatant were collected and the levels of lactate dehydrogenase (LDH), malonaldehyde (MDA) and superoxide dismutase (SOD) were assayed using commercial kits (Nanjing Jiancheng Bioengineering Institute, Nanjing, China) according to the manufacturer's protocol.

\section{Animal treatment}

The animal experiment protocols used in this study were reviewed and approved by the Institutional Animal Care and Use Committee of Southeast University. A total of 140 male Wistar rats weighing 90-110 g were purchased from the Shanghai Experimental Animal Center of Chinese
Table 2. Diet composition of animal experiment.

\begin{tabular}{lcc}
\hline $\begin{array}{l}\text { Component } \\
\text { (weight \%) }\end{array}$ & Chow diet & High-fat diet \\
\hline Casein & 23.0 & 20.0 \\
Maize starch & 32.0 & 29.0 \\
Sucrose & 31.0 & 25.3 \\
Cellulose & 4.0 & 4.0 \\
Colza oil & 5.0 & 0.0 \\
Lard & 0.0 & 10.0 \\
Egg yolk powder & 0.0 & 5.0 \\
Cholesterol & 0.0 & 1.5 \\
Bile salts & 0.0 & 0.2 \\
Mineral mix (AIN-76A) & 3.5 & 3.5 \\
Vitamin mix (AIN-76A) & 1.0 & 1.0 \\
DL-Methionine & 0.3 & 0.3 \\
Choline chloride & 0.2 & 0.2 \\
Total & 100.0 & 100.0 \\
\hline
\end{tabular}

Academy of Sciences (Shanghai, China). All animals were kept under controlled temperature $\left(20-25^{\circ} \mathrm{C}\right)$ and on a 12 $\mathrm{h}$ light/12-h dark cycle. After an adaptation period of 7 days, the Wistar rats were starved for $12 \mathrm{~h}$ and were tested the level of total cholesterol (TC) in the serum. Based on corresponding TC level and body weight, rats were randomly divided into 14 groups ( $n=10$ in each group), including chow diet group, high-fat diet group and highfat diet plus 12 edible flowers extracts (12 groups, respectively). The food composition of the diets is shown in Table 2. Twelve edible flowers extracts were administered by gavage once a day at a dose of $3 \mathrm{~g} / \mathrm{kg}$ bw. The chow diet and high-fat diet group were administered by gavage with the equivalent of distilled water. The diet and edible flowers extracts treatment lasted for 6 weeks.

\section{Serum antioxidant capacities assay and lipid profiles}

At the end of 6 weeks, the rats were fasted overnight and were anaesthetized with sodium pentothal. The blood samples were collected from the abdominal aorta. Then the serum samples were separated through centrifuging at $3000 \mathrm{rpm}$ for $10 \mathrm{~min}$. The serum MDA, SOD and glutathion peroxidase (GSH-Px) were measured using commercial kits (Nanjing Jiancheng Bioengineering Institute, Nanjing, China) according to the manufacturer's protocol. Additionally, the serum TC, triacylglycerol (TG), high density lipoprotein cholesterol (HDL-C) and low density lipoprotein cholesterol (LDL-C) were also assayed using commercial kits (Nanjing Jiancheng Bioengineering Institute, Nanjing, China) according to the manufacturer's protocol.

\section{Statistical analysis}

Each value was expressed as means \pm SD. Data were analysed using One-way Analysis of Variance 
(ANOVA). All the analyses were performed in PASW statistics 18.0 (SPSS Inc, Chicago, IL, USA). $p$ value less than 0.05 has been considered significant.

\section{Results}

\section{Antioxidant activities of edible flowers extracts}

As observed in Table 3, four different antioxidant models, including TAC, ORAC, SHRC and SSARC were used to evaluate the antioxidant activities of edible flowers extracts. Lonicera japonica Thunb. possessed the highest TAC, followed by Rosmarinus officinalis L., Chrysanthemum indicum L. and Myosotis silvatica Ehrh. ex Hoffm. Jasminum sambac (L.) Aiton is characterized by the lowest TAC, which is 4.3-fold lower than Lonicera japonica Thunb. The ORAC ranged from $46.11 \pm 0.10$ $\mu \mathrm{mol} \mathrm{TE} / \mathrm{g}$ (Jasminum sambac (L.) Aiton) to $861.87 \pm 0.25$ $\mu \mathrm{mol} \mathrm{TE} / \mathrm{g}$ (Rosa rugosa Thunb.). Chrysanthemum indicum L., Myosotis silvatica Ehrh. ex Hoffm. and Chrysanthemum morifolium Ramat. exhibited the higher SHRC with more than $1100.00 \mathrm{U} / \mathrm{g}$. The lowest SHRC was found in Rosa rugosa Thunb., Rosa rugosa Thunb., Rosmarinus officinalis L. and Chrysanthemum morifolium Ramat. showed the higher SSARC when compared with other extracts. The lowest SSARC was revealed only in Gardenia jasminoides Ellis with value of $103.02 \mathrm{U} / \mathrm{g}$.

\section{Effects of edible flowers extracts on rCMEC proliferation and apoptosis}

Upon the hypoxia $1 \mathrm{~h}$ then re-oxygenation $1 \mathrm{~h}$ treatment, there was a large decrease in the proliferation of rCMEC. The cells pre-treated with edible flowers extracts could attenuate this damage, especially in groups of Carthamus tinctorius L., Chrysanthemum indicum L. and Chrysanthemum morifolium Ramat
Table 4. Effects of edible flowers extracts on rCMEC proliferation and apoptosis.

\begin{tabular}{lcc}
\hline Group & Proliferation & Apoptosis (\%) \\
\hline Normal cell & $63.57 \pm 0.83$ & $4.58 \pm 0.41$ \\
Hypoxia-re-oxygenation cell & $24.89 \pm 1.21^{\mathrm{a}}$ & $54.04 \pm 1.91^{\mathrm{a}}$ \\
Lonicera japonica Thunb. & $22.74 \pm 0.67$ & $\mathrm{Nd}$ \\
Jasminum sambac (L.) Aiton & $26.60 \pm 1.14$ & $\mathrm{Nd}$ \\
Carthamus tinctorius L. & $45.92 \pm 0.72^{\mathrm{b}}$ & $29.06 \pm 1.18^{\mathrm{b}}$ \\
Gardenia jasminoides Ellis & $34.76 \pm 1.33^{\mathrm{b}}$ & $\mathrm{Nd}$ \\
Magnolia officinalis Rehd. et Wils. & $28.75 \pm 0.96^{\mathrm{b}}$ & $\mathrm{Nd}$ \\
Rosa rugosa Thunb. & $15.02 \pm 1.31$ & $\mathrm{Nd}$ \\
Rosmarinus officinalis L. & $28.32 \pm 0.89^{\mathrm{b}}$ & $\mathrm{Nd}$ \\
Chrysanthemum indicum L. & $52.78 \pm 1.02^{\mathrm{b}}$ & $29.88 \pm 1.27^{\mathrm{b}}$ \\
Chrysanthemum morifolium Ramat. & $51.93 \pm 0.93^{\mathrm{b}}$ & $5.04 \pm 0.27^{\mathrm{b}}$ \\
Eugenia caryophyllata Thunb. & $14.16 \pm 0.76$ & $\mathrm{Nd}$ \\
Sophora japonica L. & $39.05 \pm 1.34^{\mathrm{b}}$ & $\mathrm{Nd}$ \\
Myosotis silvatica Ehrh. ex Hoffm. & $32.61 \pm 1.32^{\mathrm{b}}$ & $\mathrm{Nd}$ \\
\hline
\end{tabular}

Values represent the means \pm SD of 5 for each group, ${ }^{\text {a }} P<0.05$ vs. Normal cell group, ${ }^{b} P<0.05$ vs. Hypoxia-re-oxygenation cell group.

$\mathrm{Nd}$, not detect.

(Table 4). We then selected the three above edible flowers extracts to measure the cell apoptosis by a flow cytometric analysis. The results showed that the cells apoptosis increased significantly in the hypoxiare-oxygenation treated group, and a certain degree of decreased cell apoptosis were found in edible flowers extracts group, especially in Chrysanthemum morifolium Ramat (Table 4).

\section{Antioxidant effects of edible flowers extracts on rCMEC induced by hypoxia-re-oxygenation}

In response to hypoxia-re-oxygenation, concentrations of circulating enzyme antioxidants such as SOD decreased, whereas LDH and MDA increased in the hypoxia-re-oxygenation cells group compared with the normal cell group (Table 5). Generally, most edible flowers extracts, with a few exceptions (like Myosotis silvatica Ehrh. ex Hoffm.), exhibited good antioxidant activities.

Table 3. Antioxidant activities of edible flowers extracts in vitro.

\begin{tabular}{|c|c|c|c|c|}
\hline Edible flowers & $\begin{array}{l}\text { TAC } \\
(U / g)\end{array}$ & $\begin{array}{c}\text { ORAC } \\
(\mu \mathrm{mol} \mathrm{TE} / \mathrm{g})\end{array}$ & $\begin{array}{l}\text { SHRC } \\
(U / g)\end{array}$ & $\begin{array}{c}\text { SSARC } \\
(\mathrm{U} / \mathrm{g})\end{array}$ \\
\hline Lonicera japonica Thunb. & $2205.2 \pm 4.6$ & $138.84 \pm 0.26$ & $969.1 \pm 6.3$ & $625.0 \pm 0.8$ \\
\hline Jasminum sambac (L.) Aiton & $517.1 \pm 3.1$ & $46.11 \pm 0.10$ & $1083.3 \pm 0.7$ & $723.4 \pm 4.1$ \\
\hline Carthamus tinctorius L. & $885.1 \pm 5.5$ & $67.38 \pm 0.12$ & $1020.3 \pm 3.8$ & $636.5 \pm 5.3$ \\
\hline Gardenia jasminoides Ellis & $1085.9 \pm 5.6$ & $60.72 \pm 0.22$ & $965.1 \pm 3.0$ & $103.0 \pm 2.0$ \\
\hline Magnolia officinalis Rehd. et Wils. & $540.6 \pm 2.0$ & $95.85 \pm 0.40$ & $1028.2 \pm 5.2$ & $760.1 \pm 3.7$ \\
\hline Rosa rugosa Thunb. & $720.9 \pm 3.7$ & $861.87 \pm 0.25$ & $724.9 \pm 1.3$ & $986.7 \pm 2.7$ \\
\hline Rosmarinus officinalis L. & $2077.5 \pm 7.9$ & $296.91 \pm 0.20$ & $984.8 \pm 2.2$ & $973.0 \pm 6.8$ \\
\hline Chrysanthemum indicum L. & $1499.5 \pm 2.9$ & $57.42 \pm 0.14$ & $1110.9 \pm 2.8$ & $666.2 \pm 3.1$ \\
\hline Chrysanthemum morifolium Ramat. & $1174.1 \pm 6.1$ & $76.32 \pm 0.30$ & $1103.0 \pm 3.0$ & $924.9 \pm 3.5$ \\
\hline Eugenia caryophyllata Thunb. & $1940.6 \pm 1.4$ & $310.23 \pm 0.19$ & $819.4 \pm 4.7$ & $615.8 \pm 1.2$ \\
\hline Sophora japonica L. & $763.5 \pm 1.8$ & $174.36 \pm 0.21$ & $1051.8 \pm 9.8$ & $709.7 \pm 1.1$ \\
\hline Myosotis silvatica Ehrh. ex Hoffm. & $1752.0 \pm 2.7$ & $98.94 \pm 0.30$ & $1107.0 \pm 4.9$ & $783.0 \pm 1.7$ \\
\hline
\end{tabular}

Values represent the means \pm SD of 3 for each group.

TAC, total antioxidant capacity; ORAC, oxygen radical absorbance capacity; SHRC, scavenging hydroxyl radical capacity; SSARC, scavenging superoxide anion radical capacity. 
Table 5. Antioxidant effects of edible flowers extracts on rCMEC induced by hypoxia-re-oxygenation.

\begin{tabular}{|c|c|c|c|}
\hline Group & $\mathrm{LDH}(\mathrm{U} / \mathrm{L})$ & $\mathrm{MDA}(\mathrm{nmol} / \mathrm{ml})$ & $\mathrm{SOD}(\mathrm{U} / \mathrm{ml})$ \\
\hline Normal cell & $138.80 \pm 11.25$ & $1.02 \pm 0.08$ & $51.61 \pm 3.43$ \\
\hline Hypoxia-re-oxygenation cell & $191.37 \pm 15.37^{\mathrm{a}}$ & $2.89 \pm 0.22^{\mathrm{a}}$ & $17.95 \pm 1.23^{\mathrm{a}}$ \\
\hline Lonicera japonica Thunb. & $172.59 \pm 7.61^{b}$ & $2.47 \pm 0.20$ & $25.57 \pm 3.60^{\mathrm{b}}$ \\
\hline Jasminum sambac (L.) Aiton & $176.59 \pm 7.61^{\mathrm{b}}$ & $2.58 \pm 0.37$ & $26.39 \pm 5.41^{b}$ \\
\hline Carthamus tinctorius $\mathrm{L}$. & $158.52 \pm 9.71^{\mathrm{b}}$ & $2.04 \pm 0.22^{b}$ & $30.85 \pm 5.35^{\mathrm{b}}$ \\
\hline Gardenia jasminoides Ellis & $168.37 \pm 10.03^{b}$ & $2.37 \pm 0.31^{b}$ & $23.83 \pm 5.49^{b}$ \\
\hline Magnolia officinalis Rehd. et Wils. & $169.19 \pm 9.73^{b}$ & $2.11 \pm 0.18^{\mathrm{b}}$ & $28.29 \pm 3.22^{\mathrm{b}}$ \\
\hline Rosa rugosa Thunb. & $158.52 \pm 8.76^{\mathrm{b}}$ & $2.55 \pm 0.24^{b}$ & $19.66 \pm 1.19$ \\
\hline Rosmarinus officinalis L. & $166.73 \pm 9.91^{\mathrm{b}}$ & $2.35 \pm 0.18^{\mathrm{b}}$ & $27.14 \pm 7.08^{b}$ \\
\hline Chrysanthemum indicum L. & $155.23 \pm 13.14^{\mathrm{b}}$ & $1.97 \pm 0.32^{\mathrm{b}}$ & $32.30 \pm 4.87^{b}$ \\
\hline Chrysanthemum morifolium Ramat. & $151.12 \pm 8.46^{\mathrm{b}}$ & $1.93 \pm 0.21^{b}$ & $34.32 \pm 5.58^{b}$ \\
\hline Eugenia caryophyllata Thunb. & $167.55 \pm 12.23^{b}$ & $2.88 \pm 0.29$ & $22.64 \pm 4.36^{b}$ \\
\hline Sophora japonica L. & $160.98 \pm 9.14^{\mathrm{b}}$ & $2.47 \pm 0.19^{b}$ & $23.32 \pm 3.32^{\mathrm{b}}$ \\
\hline Myosotis silvatica Ehrh. ex Hoffm. & $188.09 \pm 10.27$ & $2.62 \pm 0.11$ & $21.53 \pm 3.97^{\mathrm{b}}$ \\
\hline
\end{tabular}

Values represent the means $\pm S D$ of 5 for each group, ${ }^{\mathrm{a}} P<0.05$ vs. Normal cell group, ${ }^{\mathrm{b}} P<0.05$ vs. Hypoxia-re-oxygenation cell group.

$\mathrm{LDH}$, lactate dehydrogenase; MDA, malonaldehyde; SOD, superoxide dismutase.

\section{Antioxidation and lipid regulation of edible flowers extracts in hyperlipidemia rats}

In the present study, the serum MDA, TC, TG and LDL-C were increased, whereas SOD, GSH-Px and HDL-C were decreased in the experimental rats fed with high-fat diets for 6 weeks compared with those in the chow diet group (Table 6). Nevertheless, the serum MDA level was significantly declined in the groups of Lonicera japonica Thunb., Carthamus tinctorius L., Gardenia jasminoides Ellis, Magnolia officinalis Rehd. et Wils., Rosmarinus officinalis L., Chrysanthemum indicum L., Chrysanthemum morifolium Ramat. and Sophora japonica L.; the serum SOD and GSH-Px were significantly increased in the groups of Lonicera japonica Thunb., Carthamus tinctorius L., Magnolia officinalis Rehd. et Wils., Rosmarinus officinalis L., Chrysanthemum morifolium Ramat. and Eugenia caryophyllata Thunb. The aqueous extracts of Gardenia jasminoides Ellis and Magnolia officinalis Rehd. et Wils. could suppress the build-up of hyperlipidemia by reducing serum TC, TG and LDL-C, and increasing serum HDL-C.

\section{Discussion}

There are so many edible flowers all over the world that only a small part of them have been studied for their antioxidant capacities. Furthermore, little is known about the impact of edible flowers on oxidative injury including hypoxia-re-oxygenation and hyperlipidemia. In the present study, the antioxidant activities of aqueous extracts from 12 Chinese edible flowers were assessed in four different methods. Subsequently, the potential antioxidant effects on rCMEC treated with hypoxia-re-oxygenation and hyperlipidemia rats induced by high-fat diet were also evaluated.

We observed that Rosa rugosa Thunb. had the highest antioxidant capacity in both ORAC and SSARC, which was in agreement with the published studies [17-19]. Ng et al. reported the major antioxidant principles of the aqueous extract of Rosa rugosa Thunb. were associated with the presence of both gallic acid derivatives and polysaccharides [20]. In addition, the significance of antioxidant activity in

Table 6. Antioxidation and lipid regulation of edible flowers extracts in hyperlipidemia rats.

\begin{tabular}{|c|c|c|c|c|c|c|c|}
\hline Group & $\begin{array}{c}\text { MDA } \\
(\mathrm{nmol} / \mathrm{ml})\end{array}$ & $\begin{array}{c}\text { SOD } \\
(\mathrm{U} / \mathrm{ml})\end{array}$ & $\begin{array}{c}\text { GSH-Px } \\
(\mathrm{U} / \mathrm{ml})\end{array}$ & $\begin{array}{c}\mathrm{TC} \\
(\mathrm{mmol} / \mathrm{L})\end{array}$ & $\begin{array}{c}\text { TG } \\
(\mathrm{mmol} / \mathrm{L})\end{array}$ & $\begin{array}{c}\text { LDL-C } \\
(\mathrm{mmol} / \mathrm{L})\end{array}$ & $\begin{array}{c}\mathrm{HDL}-\mathrm{C} \\
(\mathrm{mmol} / \mathrm{L})\end{array}$ \\
\hline Chow diet & $3.74 \pm 0.20$ & $175.48 \pm 7.72$ & $675.48 \pm 235.38$ & $2.82 \pm 0.50$ & $1.84 \pm 0.71$ & $2.73 \pm 0.49$ & $1.89 \pm 0.49$ \\
\hline High-fat diet & $5.58 \pm 1.24^{\mathrm{a}}$ & $154.46 \pm 8.17^{\mathrm{a}}$ & $288.38 \pm 241.10^{\mathrm{a}}$ & $5.20 \pm 1.39^{a}$ & $4.02 \pm 1.03^{\mathrm{a}}$ & $5.04 \pm 1.38^{\mathrm{a}}$ & $0.87 \pm 0.25^{\mathrm{a}}$ \\
\hline Lonicera japonica Thunb. & $4.78 \pm 0.64^{b}$ & $164.45 \pm 5.56^{b}$ & $504.68 \pm 248.49^{b}$ & $4.74 \pm 0.81$ & $2.99 \pm 1.14^{b}$ & $4.62 \pm 0.80$ & $0.95 \pm 0.21$ \\
\hline Jasminum sambac (L.) Aiton & $5.04 \pm 1.12$ & $157.13 \pm 7.91$ & $349.83 \pm 82.56$ & $5.03 \pm 0.63$ & $2.74 \pm 0.92^{b}$ & $4.93 \pm 0.63$ & $1.16 \pm 0.37^{b}$ \\
\hline Carthamus tinctorius L. & $4.11 \pm 0.77^{\mathrm{b}}$ & $160.89 \pm 5.92^{b}$ & $630.48 \pm 291.26^{b}$ & $4.72 \pm 0.76$ & $2.97 \pm 1.52^{\mathrm{b}}$ & $4.62 \pm 0.77$ & $1.16 \pm 0.20^{b}$ \\
\hline Gardenia jasminoides Ellis & $4.80 \pm 1.36^{b}$ & $161.48 \pm 7.35^{b}$ & $453.39 \pm 240.53$ & $4.31 \pm 1.08^{b}$ & $2.70 \pm 0.91^{\mathrm{b}}$ & $4.22 \pm 1.09^{b}$ & $1.40 \pm 0.17^{b}$ \\
\hline Magnolia officinalis Rehd. et Wils. & $4.37 \pm 0.89^{b}$ & $160.72 \pm 8.82^{b}$ & $566.61 \pm 96.92^{b}$ & $4.33 \pm 0.83^{b}$ & $2.67 \pm 0.71^{\mathrm{b}}$ & $4.23 \pm 0.83^{b}$ & $1.48 \pm 0.38^{b}$ \\
\hline Rosa rugosa Thunb. & $4.92 \pm 0.83$ & $159.85 \pm 6.02$ & $339.19 \pm 174.24$ & $4.89 \pm 1.17$ & $3.74 \pm 0.99$ & $4.78 \pm 1.18$ & $0.91 \pm 0.13$ \\
\hline Rosmarinus officinalis L. & $4.71 \pm 0.78^{\mathrm{b}}$ & $161.68 \pm 6.10^{b}$ & $668.23 \pm 210.24^{b}$ & $4.30 \pm 0.52^{\mathrm{b}}$ & $3.25 \pm 0.51$ & $4.23 \pm 0.52^{\mathrm{b}}$ & $1.49 \pm 0.35^{b}$ \\
\hline Chrysanthemum indicum L. & $3.75 \pm 0.67^{b}$ & $159.99 \pm 7.29$ & $590.32 \pm 147.35^{b}$ & $4.25 \pm 0.70^{b}$ & $2.93 \pm 1.44^{b}$ & $4.16 \pm 0.71^{b}$ & $1.05 \pm 0.22$ \\
\hline Chrysanthemum morifolium Ramat. & $3.95 \pm 0.32^{\mathrm{b}}$ & $163.37 \pm 2.51^{b}$ & $665.81 \pm 149.37^{b}$ & $4.43 \pm 0.84$ & $4.28 \pm 1.55$ & $4.34 \pm 0.83$ & $0.94 \pm 0.12$ \\
\hline Eugenia caryophyllata Thunb. & $4.93 \pm 0.82$ & $159.85 \pm 6.02^{b}$ & $493.55 \pm 289.48^{b}$ & $5.45 \pm 1.21$ & $3.73 \pm 1.39$ & $5.33 \pm 1.22$ & $1.01 \pm 0.24$ \\
\hline Sophora japonica L. & $4.20 \pm 0.29^{b}$ & $158.20 \pm 5.83$ & $456.29 \pm 222.67$ & $5.18 \pm 0.92$ & $3.83 \pm 1.00$ & $5.07 \pm 0.93$ & $1.18 \pm 0.24^{b}$ \\
\hline Myosotis silvatica Ehrh. ex Hoffm. & $5.25 \pm 0.79$ & $156.20 \pm 6.76$ & $329.52 \pm 219.96$ & $5.30 \pm 0.94$ & $4.14 \pm 1.38$ & $5.17 \pm 0.93$ & $1.15 \pm 0.40^{b}$ \\
\hline
\end{tabular}

Values represent the means \pm SD of 10 for each group, ${ }^{a} P<0.05$ vs. Chow diet group, ${ }^{b} P<0.05$ vs. High-fat diet group. MDA, malonaldehyde; SOD, superoxide dismutase; GSH-Px, glutathion peroxidase; TC, total cholesterol, TG, triacylglycerol; HDL-C, high density lipoprotein cholesterol; LDL-C, low density lipoprotein cholesterol. 
Lonicera japonica Thunb. and Chrysanthemum indicum L. was also mentioned, for instance by Zeng et al. [21]. More recently, ethanol extracts of eight edible flowers collected in Italy were analysed for their antioxidant activities. The results show that edible flowers can serve as natural antioxidants [22]. An important thing to note is that the antioxidant effects are different based on the various extracts from edible flowers. Liu et al. found that the antioxidant capacities of the Litchi chinenesis Sonn. extracts were in a descending order as: acetone extract, methanol extract and water extract [23]. Rather, the methanol extract of Rosmarinus officinalis L. had higher antioxidant activity than its ethanol and water extract [24]. In our investigation, we only determined antioxidant activities of aqueous extract from edible flowers. This extraction is consistent with the way to have scented tea, which can be guidance for development and application of beverages made from edible flowers. However, it should be mentioned that the antioxidant activity in vitro might be regulated by food digestion and metabolism in the diet.

$\mathrm{I} / \mathrm{R}$ is a process that restores the blood flow after temporary hypoxia, and its main underlying mechanisms involve oxidative injury [25]. During the reperfusion stage, large amounts of oxygen inflowing with nutritive blood activates the hypoxanthine-xanthine oxidase system, causing overproduction of superoxide anion free radicals [26]. Although the hypoxia-re-oxygenation injury in rCMEC is one of the most important models in explaining the mechanisms involved in I/R [27], their nutraceutical application is little-studied, particularly research in edible flowers. In this study, we isolated the primary rCMEC and found that edible flowers extracts can protect rCMEC against apoptosis and alleviate impairment induced by hypoxia-re-oxygenation. Supporting our results, a previous study reported that Hibiscus sabdariffa $\mathrm{L}$. extract reduce intracellular reactive oxygen species formation of primary vascular endothelial cells and improve cell viability, following oxidative stress in dose-dependent manner [28]. At present, it is clear that these health benefits are attributed to the antioxidant activity derived from the high level of phenolic compounds present in edible flowers [15]. Besides, quercetin-3rhamnoglucoside (rutin) [29], chlorogenic acid and caffeic acid [30] play a major role in the protective effect on $\mathrm{I} / \mathrm{R}$ injury. Identification and quantification of phenolic compounds, however, are not addressed in our study. These questions are worthy of in-depth study.

High-fat diet is the direct source of oxidative stress and hyperlipidemia [31], which play critical roles in the pathogenesis of cardiovascular disease [32,33]. To counteract the oxidants, the antioxidant system attempts to boost endogenous antioxidants to protect cells from oxidative damage, which includes antioxidant enzymes such as SOD and GSH-Px [34,35]. As expected, the present study has shown that the aqueous extracts of Lonicera japonica Thunb., Carthamus tinctorius L., Magnolia officinalis Rehd. et Wils., Rosmarinus officinalis L. and Chrysanthemum morifolium Ramat. inhibit the increase in oxidative stress in high-fat diet group, characterized by the decrease of serum MDA content and the elevation of SOD and GSH-Px levels. The amount of total phenolic content and total flavonoid content seems to be responsible for much of this edible flower's efficacy as natural antioxidants [36,37]. As far as Chrysanthemum morifolium Ramat. are concerned, Luteolin 7-O-(6"O-malonyl)glucoside is a predominant flavonoid with the strongest radical scavenging activity [38]. Furthermore, it was suggested that compounds with chemical structures such as Luteolin 7-O-(6"O-malonyl)-glucoside have preventive effects against liver injury in mice induced by injection of carbon tetrachloride [39]. These results warrant further research, particularly studies dedicated to the elucidation of unidentified compounds which likely contribute to the favourable effects on antioxidant status.

Recent advances in edible flowers research have expanded the evidence for the role in modulating cardiometabolic risk factors $[40,41]$. These studies suggest that edible flowers extracts have a beneficial effect on hyperlipidemia risk factors by enhancing favorable lipid profiles. Furthermore, the flower of $P$. notoginseng and $P$. pashia have been used as traditional herbal medicine for regulating the lipid of blood in China [42,43]. In the present study, as far as Gardenia jasminoides Ellis and Magnolia officinalis Rehd. et Wils. are concerned, they show not only an antioxidant but also a marked inhibiting effects on hyperlipidemia. Unfortunately, the precise mechanisms for how edible flowers extract improved serum lipid profiles in hyperlipidemia rats were not explored. The improvement of lipid-increasing action might be accounted for by the unique nutrient composition of the edible flowers extracts.

Despite growing interest in the protective role that edible flowers may have in the development of oxidative injury and hyperlipidemia, little evidence is available in the toxicology of edible flowers. The most recent review reported that edible flowers were nontoxic at an appropriate dosage [44]. For example, an acute toxicity study in a rats model revealed that a single oral dose of $15 \mathrm{~g} / \mathrm{kg}$ bw ethanolic extract of Chrysanthemum morifolium Ramat. from china 
exhibited no observed adverse effect, and similar results were also found in the long-term toxicity study [45]. Yoo et al. found that $0.1,0.5,1.0 \mathrm{mg} / \mathrm{ml}$ ethanol extract of Lonicera japonica Thunb. showed no cytotoxicity in RAW264.7 macrophage cells [46]. Due to the limitations of the available evidence, however, further studies are warranted.

Our study had several limitations. First, different extraction methods make it difficult to investigate the relationship between antioxidant activities of edible flowers extracts and their antioxidant effects on rCMEC treated with hypoxia-re-oxygenation and hyperlipidemia rats induced by high-fat diet. Second, we did not further define the details of bioactivity responsible for the observed effects. Finally, only a single dose group is offered, so the dose-effect relationship has yet to be described. In the next study, in order to better understand how antioxidant effects of edible flowers work, it is necessary to identify and isolate the active compounds of edible flowers. The underlying antioxidant mechanisms and potential side effects of edible flowers also warrant further exploration and experimentation.

\section{Conclusions}

In this study, the antioxidant activities of aqueous extracts from 12 Chinese edible flowers were systematically evaluated by various methods in vitro and in vivo. These results indicated that the aqueous extracts of Rosmarinus officinalis L. and Chrysanthemum morifolium Ramat. possess good antioxidant effects both in vitro and in vivo. Furthermore, Gardenia jasminoides Ellis and Magnolia officinalis Rehd. et Wils. extracts markedly improved lipid metabolism in hyperlipidemia rats. Our findings highlight experimental evidence from cell models and animal-based studies that have elucidated the effects of edible flowers on the antioxidant effects and its potential application in strategies to improve oxidative stress-related diseases.

\section{Acknowledgments}

The authors gratefully acknowledge the Brunswick laboratories in Suzhou Industrial Park, China, for the laboratory and facilities supports to ORAC test.

\section{Disclosure statement}

No potential conflict of interest was reported by the authors.

\section{Funding}

This work was supported by the National Key Research and Development Plan [2016YFD0400604]; Fundamental Research Funds for the Central Universities and the Graduate Research and Innovation Projects of Colleges in Jiangsu Province [KYLX15_0175].

\section{References}

1. Ames BN, Shigenaga MK, Hagen TM. Oxidants, antioxidants, and the degenerative diseases of aging. Proc Natl Acad Sci U S A. 1993;90:7915-7922. DOI:10.1073/ pnas.90.17.7915

2. Qingming Y, Xianhui P, Weibao K, et al. Antioxidant activities of malt extract from barley (Hordeum vulgare L.) toward various oxidative stress in vitro and in vivo. Food Chem. 2010;118:84-89. DOI:10.1016/j. foodchem.2009.04.094

3. Benzie IF. Evolution of antioxidant defence mechanisms. Eur J Nutr. 2000;39:53-61. DOI:10.1007/ s003940070030

4. Yin D, Chen K. The essential mechanisms of aging: irreparable damage accumulation of biochemical sidereactions. Exp Gerontol. 2005;40:455-465. DOI:10.1016/ j.exger.2005.03.012

5. Singh U, Jialal I. Oxidative stress and atherosclerosis. Pathophysiology. 2006;13:129-142. DOI:10.1016/j. pathophys.2006.05.002

6. Botterweck AA, Verhagen H, Goldbohm RA, et al. Intake of butylated hydroxyanisole and butylated hydroxytoluene and stomach cancer risk: results from analyses in the Netherlands Cohort Study. Food Chem Toxicol. 2000;38:599-605. DOI:10.1016/S0278-6915(00)00042-9

7. Safer AM, Al-Nughamish AJ. Hepatotoxicity induced by the anti-oxidant food additive, butylated hydroxytoluene (BHT), in rats: an electron microscopical study. Histol Histopathol. 1999;14:391-406.

8. Wongwattanasathien O, Kangsadalampai K, Tongyonk L. Antimutagenicity of some flowers grown in Thailand. Food Chem Toxicol. 2010;48:1045-1051. DOI:10.1016/j. fct.2010.01.018

9. Cunningham E. What nutritional contribution do edible flowers make? J Acad Nutr Diet. 2015;115:856. DOI:10.1016/j.jand.2015.03.002

10. Kaisoon O, Siriamornpun S, Weerapreeyakul N, et al. Phenolic compounds and antioxidant activities of edible flowers from Thailand. J Funct Foods. 2011;3:88-99. DOI:10.1016/j.jff.2011.03.002

11. Mlcek J, Rop O. Fresh edible flowers of ornamental plants - a new source of nutraceutical foods. Trends Food Sci Technol. 2011;22:561-569. DOI:10.1016/j. tifs.2011.04.006

12. Fan J, Zhu W, Kang H, et al. Flavonoid constituents and antioxidant capacity in flowers of different Zhongyuan tree penoy cultivars. J Funct Foods. 2012;4:147-157. DOI:10.1016/j.jff.2011.09.006

13. Chinese Pharmacopoeia Commission. Pharmacopoeia of the People's Republic of China. Beijing: China Medical Science and Technology Press; 2015. 
14. Editorial Board of the Flora of China. Flora of China. Beijing: Science Press; 2004.

15. Xiong L, Yang J, Jiang Y, et al. Phenolic compounds and antioxidant capacities of 10 common edible flowers from China. J Food Sci. 2014;79:C517-C525. DOI:10.1111/1750-3841.12404

16. Nishida M, Carley WW, Gerritsen ME, et al. Isolation and characterization of human and rat cardiac microvascular endothelial cells. Am J Physiol. 1993;264:H639H652.

17. Cho EJ, Yokozawa T, Rhyu DY, et al. Study on the inhibitory effects of Korean medicinal plants and their main compounds on the 1,1-diphenyl-2-picrylhydrazyl radical. Phytomedicine. 2003;10:544-551. DOI:10.1078/ 094471103322331520

18. Zeng YW, Zhao JL, Peng YH. A comparative study on the free radical scavenging activities of some fresh flowers in southern China. Lwt-Food Sci and Technol. 2008;41:1586-1591. DOI:10.1016/j.lwt.2007.10.010

19. Li A-N, Li S, Li H-B, et al. Total phenolic contents and antioxidant capacities of 51 edible and wild flowers. J Funct Foods. 2014;6:319-330. DOI:10.1016/j. jff.2013.10.022

20. Ng TB, He JS, Niu SM, et al. A gallic acid derivative and polysaccharides with antioxidative activity from rose (Rosa rugosa) flowers. J Pharm Pharmacol. 2004;56:537-545. DOI:10.1211/0022357022944

21. Zeng Y, Deng M, Lv Z, et al. Evaluation of antioxidant activities of extracts from 19 Chinese edible flowers. SpringerPlus. 2014;3:315. DOI:10.1186/2193-1801-3-315

22. Loizzo MR, Pugliese A, Bonesi M, et al. Edible flowers: a rich source of phytochemicals with antioxidant and hypoglycemic properties. J Agric Food Chem. 2016;64:2467-2474. DOI:10.1021/acs.jafc.5b03092

23. Liu S-C, Lin J-T, Wang C-K, et al. Antioxidant properties of various solvent extracts from lychee (Litchi chinenesis Sonn.) flowers. Food Chem. 2009;114:577-581. DOI:10.1016/j.foodchem.2008.09.088

24. Pérez MB, Calderón NL, Croci CA. Radiation-induced enhancement of antioxidant activity in extracts of rosemary (Rosmarinus officinalis L.). Food Chem. 2007;104:585-592. DOI:10.1016/j.foodchem.2006.12.009

25. Megison SM, Horton JW, Chao H, et al. A new model for intestinal ischemia in the rat. J Surg Res. 1990;49:168-173. DOI:10.1016/0022-4804(90)90257-3

26. Schoenberg MH, Fredholm BB, Haglund U, et al. Studies on the oxygen radical mechanism involved in the small intestinal reperfusion damage. Acta Physiol Scand. 1985;124:581589. DOI:10.1111/j.1748-1716.1985.tb00051.x

27. Kurokawa T, Itagaki S, Yamaji T, et al. Antioxidant activity of a novel extract from bamboo grass (AHSS) against ischemia-reperfusion injury in rat small intestine. Biol Pharm Bull. 2006;29:2301-2303. DOI:10.1248/ bpb.29.2301

28. Micucci M, Malaguti M, Toschi TG, et al. Cardiac and vascular synergic protective effect of Olea europea L. leaves and Hibiscus sabdariffa L. flower extracts. Oxid Med Cell Longev. 2015;2015:1-14. DOI:10.1155/2015/318125

29. Itagaki S, Oikawa S, Ogura J, et al. Protective effects of quercetin-3-rhamnoglucoside (rutin) on ischemiareperfusion injury in rat small intestine. Food Chem. 2010;118:426-429. DOI:10.1016/j.foodchem.2009.04.103
30. Sato Y, Itagaki S, Kurokawa T, et al. In vitro and in vivo antioxidant properties of chlorogenic acid and caffeic acid. Int J Pharm. 2011;403:136-138. DOI:10.1016/j. ijpharm.2010.09.035

31. Anderson RA, Evans ML, Ellis GR, et al. The relationships between post-prandial lipaemia, endothelial function and oxidative stress in healthy individuals and patients with type 2 diabetes. Atherosclerosis. 2001;154:475-483. DOI:10.1016/S0021-9150(00)00499-8

32. Khan N, Khymenets O, Urpí-Sardà M, et al. Cocoa polyphenols and inflammatory markers of cardiovascular disease. Nutrients. 2014;6:844-880. DOI:10.3390/nu6020844

33. Park SH, Shim BS, Yoon JS, et al. Vascular protective effect of an ethanol extract of camellia japonica fruit: endothelium-dependent relaxation of coronary artery and reduction of smooth muscle cell migration. Oxid Med Cell Longev. 2015;2015:6309565.

34. Zhang Y-J, Gan R-Y, Li S, et al. Antioxidant phytochemicals for the prevention and treatment of chronic diseases. Molecules (Basel, Switzerland). 2015;20:2113821156. DOI:10.3390/molecules201219753

35. Zhang Y, Cao Y, Wang F, et al. 4-Nitrophenol induces activation of $\mathrm{Nrf} 2$ antioxidant pathway and apoptosis of the germ cells in rat testes. Environ Sci Pollut Res Int. 2016;23:13035-13046. DOI:10.1007/s11356-016-6470-2

36. Koike A, Barreira JC, Barros L, et al. Edible flowers of Viola tricolor L. as a new functional food: antioxidant activity, individual phenolics and effects of gamma and electron-beam irradiation. Food Chem. 2015;179:6-14. DOI:10.1016/j.foodchem.2015.01.123

37. Goya L, Martín MA, Sarriá B, et al. Effect of cocoa and its flavonoids on biomarkers of inflammation: studies of cell culture, animals and humans. Nutrients. 2016;8:212. DOI:10.3390/nu8040212

38. Sugawara T, Igarashi K. Cultivar variation in flavonoid components and radical scavenging activity of polyphenol fractions among edible chrysanthemum flowers. Nippon Shokuhin Kagaku Kogaku Kaishi. 2009;56:600-604. DOI:10.3136/nskkk.56.600

39. Sugawara T, Igarashi K. Identification of major flavonoids in petals of edible chrysanthemum flowers and their suppressive effect on carbon tetrachloride-induced liver injury in mice. Food Sci Technol Res. 2009;15:499506. DOI:10.3136/fstr.15.499

40. Khan N, Akhtar MS, Khan BA, et al. Antiobesity, hypolipidemic, antioxidant and hepatoprotective effects of Achyranthes aspera seed saponins in high cholesterol fed albino rats. Arch Med Sci. 2015;11:1261-1271. DOI:10.5114/aoms.2015.56353

41. Mulvihill EE, Burke AC, Huff MW. Citrus flavonoids as regulators of lipoprotein metabolism and atherosclerosis. Annu Rev Nutr. 2016;36:275-299. DOI:10.1146/ annurev-nutr-071715-050718

42. Yang B-R, Cheung K-K, Zhou X, et al. Amelioration of acute myocardial infarction by saponins from flower buds of Panax notoginseng via pro-angiogenesis and anti-apoptosis. J Ethnopharmacol. 2016;181:50-58. DOI:10.1016/j.jep.2016.01.022

43. He J, Yin T, Chen Y, et al. Phenolic compounds and antioxidant activities of edible flowers of Pyrus pashia. J Funct Foods. 2015;17:371-379. DOI:10.1016/j. jff.2015.05.045 
44. Lu B, Li M, Yin R. Phytochemical content, health benefits, and toxicology of common edible flowers: a review (2000-2015). Crit Rev Food Sci Nutr. 2016;56(Suppl 1): S130-S148. DOI:10.1080/10408398.2015.1078276

45. Li L, Gu L, Chen Z, et al. Toxicity study of ethanolic extract of Chrysanthemum morifolium in rats. J
Food Sci. 2010;75:T105-T109. DOI:10.1111/j.17503841.2010.01702.x

46. Yoo H-J, Kang H-J, Song YS, et al. Anti-angiogenic, antinociceptive and anti-inflammatory activities of Lonicera japonica extract. J Pharm Pharmacol. 2008;60:779-786. DOI:10.1211/jpp.60.6.0014 